\title{
DE LA LEY DE JUSTICIA Y PAZ A LA LEY DE VÍCTIMAS Y RESTITUCIÓN DE TIERRAS. DE LA INDIGNACIÓN A LA RECONCILIACIÓN.
}

\author{
FROM THE LAW OF JUSTICE AND PEACE TO THE LAW OF VICTIMS AND \\ THE RESTITUTION OF LANDS: FROM INDIGNATION TO RECONCILIATION
}

Recibido: Junio 2011 - Revisado: Agosto 2011 - Aceptado: 30 de Noviembre de 2011

Por: Oswaldo Plata Pineda

\begin{abstract}
RESUMEN:
Los enfoques de justicia transicional persiguen el propósito de restablecer las condiciones naturales de las instituciones estatales, camino de la verdad, la justicia y la reparación. En tiempos recientes, el ordenamiento jurídico colombiano incorporó dos modelos especiales y complementarios de éste enfoque de justicia (a saber, la Ley de Víctimas y Restitución de Tierras y la Ley de Justicia y Paz). A partir de un sucinto análisis de los dos modelos de justicia transicional antedichos, sugiero que la ocurrencia del conflicto armado y la existencia de víctimas evidencian la debilidad práctica del Estado Político y la fragilidad del núcleo democrático. Se define defiendo la tesis de que los modelos de justicia transicional citados solucionan parte del problema (espacios materiales de reparación), pero que ellos mismos deben ser acompañados por la sociedad civil a través de la creación de un grado de conciencia del conflicto (espacios simbólicos de reparación) inspirado en el sentimiento moral de la indignación, único posibilitador de la reconciliación.
\end{abstract}

\section{PALABRAS CLAVES:}

Justicia Transicional, Estado, Ley de Víctimas, Indignación, Reconciliación.

\section{ABSTRACT:}

The approaches of transitional justice aim to restore the natural conditions of State institutions, the way of truth, justice and reparation. At recent times, the Colombian legal system incorporated two special and complementary models of this approach of justice (i.e. the Law of Victims and Restitution of Lands and the Law of Justice and Peace). Starting from a succinct analysis of two aforementioned models of transitional justice, I suggest that the occurrence of the armed conflict and the existence of victims demonstrate the practical weakness of the political State and the fragility of the democratic core. It is defined by defending the thesis that the aforementioned models of transitional justice solve the problem partially (material areas of repair), but that they themselves must be accompanied by the civil society through the creation of a degree of awareness of the conflict (symbolic spaces of repair) inspired by the moral sense of outrage, as being the only means of reconciliation.

\section{KEY WORDS:}

State, Law of Victims, Indignation, Transitional Justice, Reconciliation.

${ }^{1}$ Licenciado (2004) y Magister (2006) en Filosofia, Universidad del Valle. Docente de Tiempo Completo Politécnico Colombiano Jaime Isaza Cadavid Medellin (Colombia). Docente Catedrático Universidad de Antioquia, Colombia. Miembro del Grupo de Investigación en Filosofia GIF. oswaldoplata10@gmail.com, ojplata@elpoli.edu.co 


\section{Introducción.}

que la LVRT era inconveniente para el país por tres razones: 1-) porque igualaba las acciones de los agentes del Estado y de los miembros de los grupos alzados en armas, 2-) porque los costos de reparación desbordaban la capacidad presupuestal del Estado y 3-) porque no existía coherencia entre las medidas de reparación y los mecánicos de restitución de tierras. Con base en esta argumentación, y a través de su presencia parlamentaria, el gobierno de marras logró que la LVRT no prosperara en el Congreso de la República. Allende esta suerte, un año después, ido Uribe y posesionado Santos, la LVRT adquirió de manera sorpresiva un segundo aire y, merced a un debate álgido, fue aprobada por amplia mayoría por el Congreso de la República el pasado 24 de mayo de 2011 .

Los desafios a los que se enfrenta la LVRT son enormes y de índole diversa, ya que apunta a solucionar el problema de la violencia de Colombia desde sus orígenes. Con todo, y aunque la LVRT busca manifiestamente devolverles a las víctimas lo que alguna vez hubo de ser suyo, la reconciliación y la paz, propósitos que subyacen a la LVRT, sólo serán posibles si las instituciones del Estado crean las condiciones materiales para que ellas puedan darse y si la sociedad es consciente de la necesidad de reconocer a las víctimas del conflicto armado como tales y de repararlas moral y materialmente. La sociedad debe por ello conocer en detalle lo que aquí sucedió, lo que ella misma padeció, a fin de que se desvele la verdad histórica, se pongan de relieve los móviles verdaderos del conflicto y se construyan espacios simbólicos y concretos de reparación. Todo lo antedicho modela un grado de conciencia del conflicto que se plantea comoel único posibilitador de la reconciliación y la paz. Se pretendecontribuir a la generación de ese grado de conciencia.

Lapresentación consta de cuatro apartados. En el primero de ellos, se subrayan algunos aspectos positivos de la LVRT que la diferencian de la LJP y que propenden por la reivindicación de las víctimas del conflicto armado colombiano. En el segundo apartado, se hace unabreve mención de la naturaleza teórica de los sistemas de justicia transicional y las dificultades(a saber, procedimentales, procesales y ético-políticas) a las que se enfrentará la LVRT en su aplicación. En el tercer apartado, sostengo, primero, que la existencia de víctimas pone en cuestión tanto la legitimidad del Estado colombiano como la solidez de su democracia y, segundo, que la solución a éste problema es política, que no sólo jurídica. En el cuarto y último apartado, con base en la idea básica que transmite la doctrina del contrato social, se defiendela tesis de que una comprensión plena del conflicto, superadora de la apatía y de la indiferencia de la sociedad, constituye la condición de posibilidad de la reconciliación y la paz.

I. Las víctimas son el objeto central de la LJP y de la LVRT. A su manera, cada legislación propende por ellas, pese a lo cual, de lo que va de la LJP a la LVRT el lugar que ocupan las víctimas es harto diferente. La LJP pretendía, en efecto, suministrar a las víctimas los elementos necesarios para elaborar sus duelos respectivos, partiendo de la convicción de que la verdad posibilitaba el perdón y la reconciliación. No obstante, una Ley sobre la verdad no implica necesariamente la materialización de la verdad. Y esto no sólo por el hecho psicológico de la mentira, lugar común de las confesiones de los postulados a la LJP, sino por el hecho sociológico mismo de la verdad, que trae consecuencias culturales, sociales y económicas. Quienes en su momento criticarón la LJP advertierón que ella estaba viciada de nulidad porque se encontraba fundada en una idea débil de perdón y porque el silogismo práctico allí establecido no tenía manera alguna de tornarse válido: Los seres humanos no pasamos así como así de la verdad al perdón, a la reconciliación y a la paz. Precisamente sobre la LJP, en un documento anterior, advertía que su contenido no generaba las condiciones necesarias 
para el perdón y la reconciliación y que, en esa medida, el propósito perseguido difícilmente se alcanzaría. Así lo afirmaba quien escribe, en el .2007:

En lo que a la Ley respecta, salta a la vista que tiene un enorme vacío, que no jurídico sino moral, que consiste en invisibilizar a las victimas todas. A las vivas cuando les asigna un lugar pasivo en la dinámica de la confesión y entiende su reparación únicamente en términos económicos; a las muertas cuando no exige de parte de sus victimarios un compromiso decidido con la verdad. La Ley no propende, en ese sentido, por el descubrimiento de una comprehensiva verdad histórica, sino por la consolidación de un proyecto de unidad nacional levantado sobre la base de acuerdos políticos soterrados, de verdades de crímenes dichas a medias y de altos niveles de impunidad y de corrupción. Además del tipo de país que configurará -uno en el que seguramente el derecho se pondrá de ordinario al servicio de intereses criminales-, lo agraviante de la Ley es que pide de la víctima un esfuerzo sobrehumano, el olvido sin más, que no se compadece con la ofensa recibida y que no es reciprocopor los victimarios con señales de honestidad y de arrepentimiento. Aunque es una realidad auto-evidente que sin verdad, no habrá justicia, no habrá duelo catalizador, no habrá reconciliación y no habrá paz, la Ley está concebida para perpetuar la impunidad y menoscabar la verdad histórica . (Pineda, 2008)

En el esquema de la LJP, las víctimas quedaban efectivamente a merced de las buenas intenciones de su victimario. Su dolor, en esa medida, no tenía cómo desaparecer con la $\operatorname{verdad}(\mathrm{y}$, mucho menos, con las mentiras sistemáticas), pues, el perdón es producto de un proceso empático entre el ofendido y el ofensor, ente la víctima y el victimario, que presupone una participación honesta, veraz y arrepentida del ofensor. En palabras de Novitz:

The willingness and the ability to see things differently and to depart from our own settled perspective is, I think, a necessary part of the task of forgiving, and requires some degree of empathic thinking.... For in order to view someone with compassion and love, one must at least try to understand that person, their reasons, feelings, and hopes, and this will invariably involve an attempt to identify imaginatively with them . (Novitz, 1998) ${ }^{3}$

De esta suerte, la dinámica del perdón no logra consolidarse si, por un lado, el ofensor no se encuentra verdaderamente arrepentido y si, por el otro, la víctima no se cerciora de la veracidad de ese arrepentimiento. La LJP constituye un fracaso porque ésta dinámica del perdón no logró concretarse. Pero, lo es, además, porque la LJP no estableció procedimientos claros para la reparación material de las víctimas. Si bien incluía consideraciones económicas para la reparación, la LJP no comprendia un elemento esencial para muchas de las víctimas que habían sido desplazadas de su lugar de origen: la restitución de sus tierras como mecanismo de reparación.

En contraste con su predecesora, la LVRT piensa de manera prioritaria en las víctimas, vivas y muertas, y establece los elementos materiales para la reconciliación nacional. Así, con objeto de consolidar un escenario inclusivo y democrático de reconciliación, la LVRT introduce un conjunto de medidas concretas para la reparación y una caracterización amplia de categoría de víctima, desligada de la concepción ideológica y/o la filiación política del victimario. El artículo $3^{\circ}$ condensa para sí esto que se acaba de decir:

Se consideran víctimas, para los efectos de esta ley, aquellas personas que individual o colectivamente hayan sufrido un daño por hechos ocurridos a partir del $1^{\circ}$ enero de 1985 , como consecuencia de infracciones al Derecho Internacional Humanitario o de violaciones 
graves y manifiestas a las normas Internacionales de Derechos Humanos, ocurridas con ocasión del conflicto armado interno. También son víctimas el cónyuge, compañero o compañera permanente, parejas del mismo sexo y familiar en primer grado de consanguinidad, primero civil de la víctima directa, cuando a ésta se le hubiere dado muerte o estuviere desaparecida. A falta de éstas, lo serán los que se encuentren en el segundo grado de consanguinidad ascendente. De la misma forma, se consideran víctimas las personas que hayan sufrido un daño al intervenir para asistir a la víctima en peligro o para prevenir la victimización. La condición de víctima se adquiere con independencia de que se individualice, aprehenda procese o condene al autor de la conducta punible y de la relación familiar que pueda existir entre el autor y la víctima (Artículo III).

En primer lugar, resulta necesario subrayar que, en el esquema jurídico de la LVRT, el reconocimiento estatal de las víctimas se efectúa con base en las infracciones tipificadas en el Derecho Internacional Humanitario y en las normas internacionales de Derechos Humanos. La correspondencia presupuesta en la LVRT es particularmente relevante porque, por vía indirecta, internacionaliza el conflicto y, por vía directa, obliga a los actores del mismo a estar a la altura de los parámetros internacionales. Cierto es que esta obligación es meramente formal y no existe manera de exigir su cumplimiento. Pero el hecho de ubicar en la palestra pública internacional el conflicto armado interno constituye un avance significativo, y sin precedentes, cuyo importe político todavía está por mensurar. Resulta, en todo caso, no menos que vergonzante que habiendo padecido los rigores de un conflicto de cuatro décadas, habiéndonos convertido en el segundo país con mayor número de desplazados y de haber traspasado todos los límites morales de la guerra, tan sólo ahora nos hayamos decidido a concebir una ley para la paz-allende la persistencia del conflicto persiste-compatible con los estándares jurídicos internacionales. Claro está, mejor tarde que nunca.

En segundo lugar, la cita transcrita línea atrás alberga otro aspecto relevante que tiene que ver con la manera como la categoría "víctima" es concebida de manera independiente del victimario y se extiende a agentes indirectos, es decir, a aquellos que no siendo destinatarios del acto violento también sufrieron sus consecuencias. La LVRT entiende, en este sentido, que víctimas indirectas pueden ser "el cónyuge, compañero o compañera permanente, parejas del mismo sexo y familiar en primer grado de consanguinidad [y quienes] hayan sufrido daño al intentar ayudar a una víctima". Esa definición de víctima, que también podría llegar a cobijar al círculo próximo de los victimarios, es, sin duda, un aspecto innovador que juega a favor de la reconciliación, pues los familiares de los victimarios son, quiérase o no, también víctimas del conflicto ${ }^{5}$.

En tercer lugar, la cita menciona una fecha paradigmática (primero de enero de 1985), la cual, tras una álgida discusión, motivada principalmente por los parlamentarios del Partido Liberal y el Polo Democrático Alternativo, fue concertada en el Congreso de la República. Esta fecha constituye una conquista, si bien pírrica, de la LVRT; de haber prosperado la postura contraria, que planteaba el año de 1991 como punto de referencia cronológico, hoy tendriamos una LVRT esencialmente injusta y fundada en un error histórico. Ello debido a que fue precisamente en el período que va de 1980 a 1991 en el que aconteció el asesinato sistemático de un partido político (la Unión Patriótica), en él tuvieron lugar las primeras masacres de los grupos alzados en armas, en el que presentaron los primeros casos de desplazamiento forzoso y en el que la sociedad civil comenzó a padecer la lucha entre los carteles de la droga. Por descontado, la fecha continúa siendo problemática, toda vez que en Colombia existe una larga tradición de violencia extrema y existen casi cuatro generaciones víctimas. 
De lo dicho hasta aquí, se concluye que la LVRT constituye una apuesta sin paragón en la historia de Colombia por "establecer medidas en todos y cada uno de los componentes de la reparación (restitución, compensación, satisfacción, rehabilitación y garantías de no repetición)". Su principal bondad es la creación de un sistema judicial y administrativo para que las víctimas reclamen las tierras que les fueron usurpadas "de manera expedita y con algunas ventajas derivadas de la flexibilización de cargas probatorias y la creación de presunciones de despojo" (Uprimny R. \& Sánchez C, 2011). Pese a sus vacíos procedimentales y cronológicos, sus déficits conceptuales y su alto impacto fiscal, la LVRT remedia los yerros de su predecesora y crea las condiciones preparatorias para la reconciliación. En todo caso, ello será insuficiente si el Estado no adelanta medidas "concretas y específicas que vayan más allá de la entrega disfrazada de unos beneficios sociales o unos reconocimientos vacíos" y $\mathrm{si}_{\text {。 }}$ sobre todo, la sociedad no acompaña activamente el conjunto general del proceso.

II. Los procesos de justicia transicional tienen por objeto restablecer las condiciones naturales de las instituciones estatales, camino de la verdad, la justicia y la reparación. En rigor, no constituyen un tipo especial de justicia, sino, un sistema de justicia adecuado a sociedades en las que han ocurrido violaciones sistemáticas a los derechos humanos. Así, buscando crear las condiciones para la convivencia pacífica, plantean la necesidad de a-) adelantar una reconstrucción de los acontecimientos -mediante los testimonios de los victimarios- con objeto de desvelar la verdad histórica y de asignar responsabilidades individuales y colectivas, y de b-) reconocer y de reparar social e institucionalmente a las víctimas.

Pese a la fuerza moral del propósito fundamental de la LVRT, el camino de su realización se halla, según se anticipara, provisto de dificultades de índole diversa. La primera de ellas (procedimental) se relaciona con la capacidad operativa del Estado para hacerle frente a la resistencia, pública o velada, de aquellos sectores de la sociedad que se beneficiaron -y se benefician aún- del conflicto y la violencia . En virtud de esto, cabe preguntarse si las instituciones jurídicas y sociales del Estado están en capacidad de cumplir con las actividades relacionadas con la expropiación y la restitución; y si los organismos de seguridad están preparados para garantizar el orden público en aquellas zonas geográficas en las que los poderes de titulación de la tierra sean restituidos. Tales inquietudes son, naturalmente, del resorte de las instituciones del Estado (Fuerzas Militares, Policía, Fiscalía General de la Nación, Procuraduría General de la Nación, Defensoría del Pueblo y las recientemente creadas Unidad Administrativa Especial de Atención y Reparación de Víctimas, Unidad de Restitución de Tierras Despojadas y Centro de la Memoria Histórica). Parece razonable suponer que una iniciativa surgida del ejecutivo, que no sectores minoritarios del legislativo, contará con todo el apoyo logístico y económico necesario. Confirmación de esto último son las palabras del Ministro de Hacienda y Crédito Público, Juan Carlos Echeverry:

El Gobierno ha iniciado el cumplimiento de la Ley de Víctimas y de Restitución de Tierras. El proyecto de presupuesto del 2012 contempla más de 3,8 billones de pesos, en los rubros para población desplazada, la política de víctimas de la violencia y restitución de tierras. Adicionalmente, los sistemas de salud y educación atenderán a los adultos, jóvenes y niños de éstas familias, con un gasto adicional cercano a un billón y medio de pesos por año. El Gobierno destinó también más de 400 mil millones de pesos $(\mathrm{mm})$ para contingencias, en el marco de esta politica . 
Desde luego, a las instituciones que tienen en sus manos la aplicación de la LVRT les compete, en definitiva, hacer respetar -con base en el código penal o en el contenido de este tipo de justicia transicional- la observancia de los acuerdos alcanzados. Si bien nada garantiza que la expropiación y la restitución serán procesos exitosos, ahora, por lo menos, contamos con las herramientas jurídicas para hacerlo. La segunda dificultad (procesal) tiene que ver con la manera como la LVRT y la LJP se articulará con el ordenamiento jurídico vigente. En su aplicación, ¿se derogarán leyes o se traslaparán entre sí? Esto atañe a la estructura básica de la LVRT y acusa un vacío que los proponentes no supieron resolver o no lograron advertir. Con todo, este tipo de problemas se resolverán a través de la práctica consuetudinaria; será ella la que arroje luz sobre la relación de la LVRT y la LJP con otras leyes vigentes. Sea lo que fuere, el espíritu de la LVRT, que es la consecución de la paz mediante la creación de las condiciones materiales de posibilidad, deberá primar sobre la letra de la misma, y cualquier choque entre legislaciones deberá ser dirimido a favor de la LVRT.

La tercera dificultad (ético-política) ha sido advertida también por expertos (Uprimny, Valencia, López, Sánchez). En opinión de ellos, si se desea que los sistemas de justicia transicional (como la LVRT) arrojen resultados satisfactorios, la sociedad entera deber ser involucrada en su dinámica de aplicación. Dicho sector, agente indirecto del conflicto, es una pieza clave del proceso de reconciliación y paz, en la medida en que la reparación de la víctimas no sólo es económica, sino, además, simbólica. La reparación material correrá por cuenta del Estado, pero es a la sociedad a quien le corresponderá reparar simbólicamente a las víctimas. Esta reparación simbólica de las víctimas constituye la condición de posibilidad de la reconciliación y la paz, y anticipa la idea sustantiva de este documento: que el éxito de la LVRT depende factores políticos, que no sólo jurídicos.

III. Al inicio de este estudio, se planteóque la existencia de víctimas en el interior de un Estado ponía manifiestamente en entredicho su legitimidad. Pues, si como lo concibieron los filósofos modernos el Estado es un artificio creado para proteger a sus ciudadanos, algo debió haber pasado con los fundamentos de su constitución en Colombia para que las torturas, las masacres y los desplazamientos hubieran tenido lugar. Por eso, si el Estado colombiano no aseguró en el pasado inmediato lo básico, que es la vida, parece razonable cuestionar, siguiendo a Hobbes, su legitimidad, en la medida en que la autoridad "concedida por cada individuo particular en la república, administra tanto poder y fuerza que por terror a ello resulta capacitado para formar las voluntades de todos en el propósito de paz en casa y mutua ayuda contra los enemigos del exterior" (Hobbes, 1983). Ahora, si el argumento hobbesiano es válido, la incapacidad de Estado para cumplir su propósito fundacional deviene inmediata en la disolución del pacto y en el desmoronamiento de las instituciones regidas por el Soberano. Nuestro caso, empero, parece no validar este razonamiento de inspiración hobbesiana, pues, una larga tradición de violencia no ha devenido en la disolución del Estado; acaso sí en su debilitamiento.

Colombia es un país lleno de ambigüedades. Tiene una larga historia de democracia ininterrumpida; en la mayor parte del siglo, sus líderes han sido impecablemente civilistas y han surgido de elecciones periódicas, en la gran mayoria de las cuales los partidos han luchado para alternarse en el ejercicio del poder. Colombia también ha evitado el ciclo de bonanzas y bancarrotas que han afligido a sus vecinos. Mediante un prudente manejo fiscal. Escapó en lo fundamental a la crisis de la deuda de América Latina en los años ochenta y no se vio obligada a reestructurar su deuda internacional. Pero, Colombia también tiene una tradición de violencia extrema (Kissinger H, 2000). 
¿Cómo explicar, entonces, esta "anormal convivencia de estabilidad y violencia"? Pizarro Leongómez considera que esta anormal convivencia de estabilidad y violencia ha erosionado las bases fundacionales del Estado colombiano, pero no al punto de hacerlo colapsar. A fin de arrojar luz sobre ésta cuestión, en Una democracia asediada. Balance y perspectiva del conflicto armado en Colombia. Pizarro Leongómez cita a algunos autores que han diferenciado conceptualmente entre Estados débiles (Weak States) y Estados fantasmas (Shadows States),describiendo aquellos como territorios en los que existe un deterioro creciente de la seguridad, y a éstos como territorios en los que no existe gobierno central ni autoridad legitima alguna. De acuerdo con los criterios establecidos, a saber, el acervo histórico de las instituciones y la índole de conflictos culturales, Leongómez advierte que Colombia se ajusta a la primera categoría y que, en esa medida, es posible sostener que Colombia es un Estado "pequeño, pobre, débil" pero no colapsado. La homogeneidad cultural de su territorio aleja la posibilidad de un escenario de conflicto de orden cosmovisivo, las instituciones dan testimonio de un largo proceso de construcción del Estado-Nación, y una compulsa de la estructura jurídica demuestra todo menos que el colapso del Estado colombiano. El ordenamiento jurídico en Colombia es complejo, a veces difuso y enrevesado, pero no precario en leyes, en códigos y en jurisprudencia. Asimismo, la Constitución Política de 1991 y las recientemente formuladas LJP y LVRT constituyen un bloque normativo que defiende formalmente lo humano, y entroniza los derechos y las libertades básicas.

En vista de lo anterior, el origen del problema tiene que ser buscado en otro lugar, no ya en los fundamentos rectores del Estado sino en la manera como éste actuó y en la forma como la sociedad acompañó tal actuación. En las palabras que daban inicio a este documento, sostenía que la efectividad de sistemas de justicia transicional como la LVRT dependia, de un lado, de la capacidad del Estado para crear las condiciones materiales de la reparación y, del otro lado, de la participación activa del conjunto general de la sociedad en la creación de espacios simbólicos de reparación. De hecho, si la sociedad no es consciente del dolor de las víctimas, dificilmente el objetivo fundamental de la LJP y LVRT, que es la reconciliación y la paz, se alcanzará. De acuerdo con lo expresado líneas atrás, el meollo del asunto tiene que ver menos con legislaciones e instituciones que con el grado de conciencia que la sociedad tuvo y tiene del conflicto. Esto se relaciona, sin duda, con las prácticas democráticas de la sociedad colombiana, signadas éstas por la apatía. Apatía frente al desarrollo del conflicto y apatía frente al devenir democrático. Salvo algunos episodios representativos, que no pasan de ser acontecimientos aislados (marchas, manifestaciones, olas verdes), la participación de la sociedad civil fue precaria, cuando no tibia. Algunos analistas han sostenido que este comportamiento es consecuencia de una comprensión reductiva de la democracia, que la limita a ser un procedimiento, decisión que se pone en juego solamente en los comicios electorales.

Hay tres clases de países, los que tienen democracia, los que no la tienen y los que creen tenerla. Sospecho que nosotros pertenecemos al tercer grupo. Nuestros dirigentes suelen reivindicar frente al mundo la más larga tradición democrática de América Latina: dos antiguos partidos políticos, la división de los poderes públicos, la prensa libre, el régimen de libertades, "el ejercicio de la propiedad privada y de los demás derechos adquiridos con justo título". Cada cuatro años, en el último siglo hemos tenido urnas electorales abiertas para los ciudadanos varones, y desde hace medio siglo también para las mujeres (Ospina W, 2011).

No obstante esto, lejos de ser un mero procedimiento, la democracia (liberal) constituye un escenario en el que los poderes autonómicos de los ciudadanos se activan, con objeto de 
reivindicar el sistema de creencias propio y, extensivamente, el ajeno. De hecho, en una verdadera democracia, "la discusión y la concertación de compromisos son, por ello, una dimensión consustancial e irrenunciable [...] que exige que la política sea concebida como una competencia pacífica entre adversarios que se reconocen legitimidad recíprocamente, y no como una lucha a muerte entre enemigos irreconciliables, pues, como resulta evidente, mayoria y minorías han de estar de acuerdo al menos, en dirimir sus diferencias democráticamente" (Woldenberg J, 2001).

En A theory of justice (Rawls, 1979) y Political Liberalism (Rawls, 1995), John Rawls formula una teoria de la democracia de éste tipo. Según éste filósofo neokantiano norteamericano, los ciudadanos ostentan la doble capacidad de elegir (racionalmente) su proyecto de vida y de convivir (razonablemente) con sus pares. Ambas dimensiones de la razón humana requieren un escenario idóneo de realización, que es la democracia, y un tipo distintivo de comunicación entre los ciudadanos, que es la razón pública. ${ }^{6}$ Rawls plantea, de este modo, la imposibilidad de la autonomía aislada -vale decir, independiente- del otro (entorno): el núcleo democrático no se activa allende los demás. La libertad política está, en esa medida, en conexión directa con los demás y da lugar a lo que Rawls denomina consenso traslapado (e hipotéticamente, posición original) y Kant denominó reino de los fines. ${ }^{7}$

Es esta libertad la que, en una perspectiva político-jurídica, modela a-) los principios constitutivos del Estado democrático liberal y la que b-) dinamiza en la arena pública el flujo constante de posturas políticas. De esta suerte, y en vista de que los principios racionales son la resultante de un acuerdo entre sujetos racionales, la dinámica democrática, expresada consuetudinariamente en la relación entre los ciudadanos, debe, por necesidad, reflejar la racionalidad de las partes. Racionalidad ésta que en Rawls, como en Kant, implica la existencia moral con el otro. De ahí que el ejercicio de los poderes ciudadanos precise del otro y que, por tanto, la democracia sea incompatible con la indiferencia y la apatía.

En las obras que componen su obra práctica, Kant emplea ésta existencia moral con el otro para postular un modelo de fundamentación de la politica y del derecho, que proclama el valor absoluto del hombre a partir del concepto inmanente de dignidad humana (dignitas hominis). Tal concepto constituye para él el punto de partida de la armonía social:

El respeto que yo tengo por otro, o que otro puede exigir de mí es el reconocimiento de una dignidad en los demás hombres, es decir de un valor que no tiene ningún precio, ningún equivalente con el que se pueda intercambiar el objeto de estimación. Cada hombre tiene el derecho de exigir el respeto de sus similares; recíprocamente, está obligado él mismo al respecto de los demás. La humanidad en sí misma es una dignidad, porque el hombre no puede ser tratado por nadie (es decir, ni por otro ni por el mismo) como un mero medio, sino que debe ser tratado siempre al mismo tiempo como un fin; precisamente en esto consiste (su personalidad), gracias a la cual no sólo se eleva por encima de todas las cosas. Puesto que el hombre no se puede vender por ningún precio [...] está obligado a reconocer prácticamente la dignidad de la humanidad en cada uno de los demás seres humanos (Kant I, 1993).

A la luz del texto kantiano, queda claro que la dignidad humana posibilita las bases sociales del auto-respeto y del respeto para con los pares; su observancia no es opcional en el seno de un sistema democrático. Es por esta razón que -y ligando esta doctrina moral al tema que nos ocupa-la existencia de víctimas pone directamente en cuestión la validez del núcleo democrático pero, sobre todo, la índole moral de la sociedad: una sociedad que convive con el 
dolor y no hace nada para repararlo es una sociedad que ha extraviado su norte moral y que ha perdido la capacidad de indignación (Ospina W, 2011).

La indignación es, en efecto, un concepto moral que transmite como ninguno otro la idea básica de la moral kantiana, puesto que quien se indigna reconoce que el tratamiento de que está siendo objeto es esencialmente injusto, pues está siendo medio y no fin del otro. La indignación traspasa el ámbito subjetivo, como quiera se extiende a los otros cuando éstos son objeto de ofensa o tratamiento inmoral. La indignación es así tanto la reivindicación racional de la dignidad humana como la configuración de un estadio emocional -que estriba en sentir en carne propia las ofensas de que es objeto otro.

IV. El grado de conciencia del que hablaba al inicio tiene que ver directamente con el sentimiento moral de la indignación. Dicho grado de conciencia presupone la existencia moral con el otro (esto es, las víctimas) y, consiguientemente, la construcción colectiva de espacios simbólicos de reconocimiento. En el caso colombiano, sólo hasta tanto esa deuda moral con las víctimas no sea saldada, nuestra democracia seguirá acusando los defectos de antaño y ellas seguirán siendo invisibilizadas. Los modelos de justicia transicional adoptados por el Estado colombiano, LJP y LVRT, contribuyen manifiestamente a saldar la deuda moral con las víctimas, pero serán insuficientes si la sociedad no comprende el drama de las víctimas y si no se indigna con todo lo que aqui ocurrió.

La comprensión no significa negar lo que resulta afrentoso, deducir de precedentes lo que no tiene tales o explicar fenómenos por tales analogías y generalidades que ya no pueda sentirse el impacto de la realidad y el shock de la experiencia. Significa, más bien, examinar y soportar conscientemente la carga que nuestro siglo ha colocado sobre nosotros - y no negar sus existencia ni someterse mansamente a su peso-.La comprensión, en suma, significa un atento e impremeditado enfrentamiento a la realidad, un soportamiento de ésta, sea lo que fuere (Arendt H, 2002).

Creo que la clave para desarrollar la comprensión antedicha en las personas que no fueron víctimas directas del conflicto puede pensarse a través de la doctrina del contrato social (Rawls, 1995),doctrina ésta que permitiría pensar históricamente la sociedad y recabar en lo que ésta ha sido a fin de no volver a serlo. ${ }^{8}$ Dada su fertilidad filosófica, ella permite ilustrar la manera como se podría concretar, merced a un acuerdo fundacional basado en el sentimiento moral de la indignación, la reparación simbólica de las víctimas $y$, eventualmente, la reconciliación y la paz. La forma, el procedimiento hipotético en sí, es lo de menos; el fondo, el contenido discursivo, es lo de más, pues estaria orientado a: -a) identificar las causas objetivas del conflicto, b-) advertir los errores, individuales y colectivos, cometidos, c-) establecer las condiciones actuales del conflicto, y d-) allanar el camino hacia la reconciliación. La tesis que subyace a este proceso es, se reitera, el sentimiento moral de la indignación permite comprender la índole del conflicto (a través del esclarecimiento de sus protagonistas y del rol desempeñado durante el conflicto). En tanto que esto será imposible de alcanzar por sí solo (y la experiencia vivida así lo corrobora), la verdad es el punto de partida y la fuerza dinamizadora y, proceda de quien proceda, debe tener por destinatarios tanto al conjunto de las víctimas como a la sociedad en pleno.

Según se aprecia, esta versión rudimentaria del contrato se diferencia de manera ostensible del contrato ralwsiano, ya que se cimenta en la posesión de información por parte de los contratantes. Así, en lugar de restringir el influjo de las cargas informacionales (Nino C, S, 
1998), (Mulhall S \& Swift J, 1992), el esbozo de contrato aquí sugerido busca socializar al máximo una información que no es conocida por todos. La razón de ser de este manejo no taxativo de la información se debe a que el objetivo es moral y no racional (Rawls) y a que no se considera que la moralidad sea tributaria de la racionalidad.

La de Rawls es una postura más compleja, ya que el velo de ignorancia imbuye la imparcialidad moral los cimientos de los principios politicos, y lo hace de un modo que se corresponde, según él, con un punto de vista de imparcialidad (<pureza del corazón $>$ ) que cualquier persona puede adoptar en cualquier momento, por bien que habitualmente no lo hagamos (Nussbaum M, 2006).

En efecto, en contra de la postura rawlsiana, ésta versión elemental del contrato no comparte la tesis de que el influjo las cargas informacionales afecta el juicio de los contratantes. Considera, más bien, que la información (la verdad, quiero decir) posibilita la estructura procedural del contrato, en tanto que ella es su núcleo y fuerza dinamizadora. De esta suerte, si en la teoría ralwsiana el objeto de acuerdo es la justicia y el resultado final son los principios de justicia, en ésta versión del contrato, la verdad es el objeto de acuerdo, la indignación su condición de posibilidad y la reparación simbólica de las víctimas el resultado final.

Se ha dicho que ésta idea rudimentaria del contrato persigue el propósito moral de reparar moralmente a las víctimas. Creo, sin embargo, que para lograr este objetivo capital deben confluir dos circunstancias especiales: la participación activa:

1-)del aparato del Estado, propendiendo por crear (y asegurar) las condiciones materiales de reparación,y..

2-) de la sociedad, en el marco de un escenario contractual, que permita, según se he sostenido, la indignación y la comprensión de las circunstancias específicas del conflicto armado (v.gr. los vejámenes de la violencia, los rigores de la guerra). Sin tal socialización de la verdad, no creo posible la indignación; y sin la ocurrencia de este sentimiento moral, no hallo posible la reconciliación entre las víctimas, los victimarios y la sociedad en pleno. Si bien el articulado de la LVRT y parcialmente el de la LJP sientan las bases para realizar parte de lo que acabo de decir (1), si la sociedad no crea espacios amplios para tramitar la verdad (de víctimas y victimarios) no se generará en su seno un sentimiento general de indignación respecto de lo sucedido a las víctimas. Mientras estas dos circunstancias no confluyan, los propósitos fundamentales de la LVRT y la LJP serán difíciles de alcanzar. 


\section{Referencias Bibliograficas}

Arendt H, (2002) Los orígenes del totalitarismo. 1 Antisemitismo (trad. Guillermo Solana), Alianza Editorial, Madrid,.

Buchanan JM, (2010) The Limits of Liberty: Between Anarchy and Leviathan, University of Chicago Press, Chicago, (1975). En castellano: Los limites de la libertad. Entre la anarquía y el Leviatán (trad. Verónica Sardón), Kata Editores. Madrid.

Echeverry, J. C. (12 de 03 de 2013). La restitución de la Paz. Recuperado el 30 de 01 de 12, de El Tiempo: http://m.eltiempo.com/opinion/columnistas/otroscolumnistas/larestitucin-de-la-paz/10239207

Londoño, F. (01 de 06 de 2011). Todo pantomima. Recuperado el 1 de 10 de 2011, de la hora de la verdad: http:/ / www.lahoradelaverdad.com.co/post/detail=6138\&_id=73.

Kant I, (1993) Metafisica de las costumbres (trad. Adela Cortina Orts), Altaya, Barcelona, 600-601.

Kissinger H, (2000) Does America Need a Foreign Policy? Toward a Diplomacy for the 21 st Century, Simon\&Schuster, New York, p.89, citado por PIZARRO

Leongómez E, (2004) Una democracia asediada. Balance y perspectiva del conflicto armado en Colombia, Norma. Bogotá.

Nino C.S, (1998) "Liberalismo versus Comunitarismo", Revista del Centro de Estudios Constitucionales núm. 1, p.371. En inglés: "The Communitarian Challenge to Liberal Rights", Law and Philosophy, núm. 8.

Novitz D. (1998), "Forgiveness and Self-Respect, Philosophy and Phenomenological Research, LVIII.2, p.309.

Nozick R, Anarchy, State, and Utopia, Basic Books, New York, 1974. En castellano: Anarquía, Estado y Utopía, Fondo de Cultura Económica, México, 1992.

Nino C, S (1998), "Liberalismo versus Comunitarismo", Revista del Centro de Estudios Constitucionales núm. 1, septiembre-diciembre, 1998, p.371.

Nussbaum M, (2006) The frontiers of justice, The Belkamp Press, Harvard University Press, 2006. En castellano: Las fronteras de la justicia. Consideraciones sobre la exclusión, Paidós, Estado y Sociedad.

Mulhall S \& Swift J. (1992), Liberals and Communitarians, Blackwell, Oxford, UK \& Cambridge,

Ospina W, (2011) “perfeccionando la democracia”, El Espectador, 20 de febrero. En internet en http://www.elespectador.com/impreso/columna-251933-perfeccionandodemocracia. 
Ospina W, (2011) “González Tomas", El Espectador, 18 de septiembre, en internet en http://www.elespectador.com/impreso/opinion/columna-299942-tomas-gonzalez

Plata Pineda O, (2008) “Comprender para perdonar. Consideraciones al fundamento moral de la Ley de Justicia y Paz", Filosofia del Derecho: Derecho y Justicia, Editorial Universidad del Cauca, pp. 137-154.

Rawls J, (1979) A Theory of Justice, Harvard University Press, 1971. En castellano: Teoria de la Justicia (trad. María Dolores Gonzáles), Fondo de Cultura Económica, México.

Rawls J, (1995) Political Liberalism, Harvard University Press, (1993). En castellano: Liberalismo Político (trad. Sergio René Madero Báez), Fondo de Cultura Económica, México.

Uprimny R, Sánchez C, Ley de Víctimas: avances, limitaciones y retos. en internet en: http://www.dejusticia.org/index.php?modo=interna\&tema=justicia_transicional\& publicacion $=1006$.

Woldenberg J, (2001) Principios y valores de la democracia), 5 ed., México, Instituto Federal Electoral.

Mulhall S, Swift J, (1992) Liberals and Communitarians, Blackwell, Oxford, UK \& Cambridge.

Hobbes T, (1983) Leviatán o la materia, forma y poder de una república eclesiástica y civil (trad. C. Moya y A. Escohotado), Editora Nacional, Madrid.

Verdad Abierta. (08 de 06 de 2011). A Ana Fabricia Córdoba la Persiguió la Violencia. Recuperado e 130 de 01 de 2012 , de Verdad A bierta: http://www.verdadabierta.com/index.php?option=com_content\&id=3313

Notas

${ }^{2}$ La advertencia lanzada hace unos años ha sido lamentablemente corroborada conforme se llevan a cabo las confesiones de los postulados a recibir los beneficios de la LJP. Después de seis años, el balance en materia de verdad es pobre e indignante: de los 31600 desmovilizados tan solo 3600 ha sido postulados y de éstos solamente 600 han comparecido. Del conjunto de desmovilizados, 1200 han sido asesinados y 1600 han sido recapturados por estar involucrados nuevamente en actividades ilegales. Pese a la entrada en vigencia de la LJP, las autoridades confirmaron recientemente que aún siguen operando 70 grupos paramilitares en 25 departamentos.

${ }^{3}$ Novitz formuló un modelo que considera que el perdón se vincula a la idea del comprender empático (empathic understanding). Para él, el perdón tiene que ver con el cambio de nuestras emociones y con la comprensión de las acciones incorrectas del punto de vista del agresor, en el contexto su propia vida. En esta perspectiva de análisis, el verdadero perdón supone sentimientos como la compasión y el amor, que facilitan la comprensión de la perspectiva del ofensor, condición necesaria del perdón.

${ }^{4}$ En lo fundamental, la LVRT propone un conjunto de medidas orientadas a la reparación moral y material de las victimas del conflicto armado. Se compone de un capitulo inicial en el que exponen los principios generales. A éste le siguen varios capitulos consagrados a la exposición de a-) la participación de las víctimas en los procesos judiciales, b-) las medidas de protección y seguridad de todos los intervinientes en el proceso de reclamación de tierra, c-) las políticas de atención y asistencia a los reclamantes, d-) los procesos de restitución de las tierras usurpadas, e-) las normas especiales para niños desmovilizados y f-) normas adicionales de participación.

${ }^{5}$ En todo caso, en lo que respecta a los victimarios, la definición de víctima que ofrece la LVRT aún se queda corta, ya que no define la situación 1-) de los actores del conflicto que, en alguna medida, también se consideran víctimas del mismo, y 2-) de aquellos agentes que, habiéndose desmovilizado, volvieron a la ilegalidad. 
${ }^{6}$ En Political Liberalism, Rawls ofrece una descripción más amplia de este concepto. Alli dice: "La razón pública, pues, es pública de tres maneras: como razón de los ciudadanos en cuanto tales, es la razón del público; su objeto es el bien público y cuestiones de justicia fundamental; y su naturaleza, su contenido es público, y está dado por los ideales y principios expresados por la concepción de la justicia política que tiene la sociedad, ideales y principios desarrollados, sobre esa base, de un modo abierto y visible".

${ }^{7}$ En la primera formulación del imperativo categórico, que reza "obra según la máxima a través de la cual puedas querer al mismo tiempo que se convierta en una ley universal", Kant sostiene que la universalidad y la necesidad absoluta de una máxima están determinadas por la racionalidad de su creador y por el procedimiento que la antecede. En esta primera formulación, Kant sólo compromete al sujeto que se somete al ejercicio del imperativo, esto es, al yo. La posibilidad de elevar la máxima de ese sujeto (yo) al estatuto de ley moral universal es concentrada por Kant en la facultad de raciocinio y en la capacidad de abstraerse de los fines privados y de resistirse a sus resortes más íntimos. El otro-yo en este desarrollo está sobrentendido en la enunciación del imperativo en la medida en que, al igual que el yo, está dotado de la misma facultad de raciocinio y de la misma capacidad de abstracción. La facultad de razonar, en tanto que canon del entendimiento, cobija a la vez al yo y al otro-yo. Para Kant, el punto de unión entre el yo y el otro-yo no son, en ese sentido, ni las inclinaciones ni los propósitos vitales sino, más bien, la facultad de determinarse a sí mismo en orden a actuar de conformidad a leyes morales universales. Ese punto de unión es el que posibilita el enlace sistémico del reino de los fines, ámbito que congrega el conjunto general de todos los fines de todos los seres racionales: "Por reino entiendo el enlace sistémico de distintos seres racionales por leyes comunes. Pues bien, dado que las leyes determinan los fines según su validez universal, tenemos que si se abstrae de las diferencias personales de los seres racionales, e igualmente de todo contenido de sus fines privados (tanto de los racionales como fines en si, como también de los fines propios que cada cual pueda ponerse a sí mismo) en conexión sistemática, esto es, un reino de los fines que es posible según los principios anteriores.

${ }^{8}$ En su esencia, la doctrina del contrato social es moral y no sólo política. La génesis de la argumentación política de los contractualistas así lo demuestra. Todos, sin excepción, parten de una caracterización de lo que el hombre es. Unas veces positiva, otras veces negativa, la argumentación nace de un caracterización antropológica que con posterioridad es empleada para explicar la manera como los hombres conviven en el interior de una sociedad. La doctrina clásica del contrato social buscaba asi fundamentar las bases del poder político, estableciendo las pautas generales de convivencia, trazando los límites de los derechos y las libertades, y diseñando los aspectos generales de las instituciones del Estado. 
